\title{
Inflammatory cytokines and sleep parameters response to life style intervention in subjects with obese chronic insomnia syndrome
}

\author{
Fadwah M Al-Sharif ${ }^{1}$, Shehab M Abd El-Kader ${ }^{2}$
}

\begin{abstract}
1. Department of Medical Laboratory Technology, Faculty of Applied Medical Sciences, King Abdulaziz University, Jeddah, Saudi Arabia.

2. Department of Physical Therapy, Faculty of Applied Medical Sciences, King Abdulaziz University, Jeddah, Saudi Arabia.
\end{abstract}

\begin{abstract}
Background: Chronic primary insomnia is a prevalent sleep disorder that is associated with adverse effects on health outcomes. Sleep disturbance is usually associated with abnormal level of systemic inflammation biomarkers.

Objective: The aim of this study was to detect changes in sleep quality and inflammatory markers following weight loss among subjects with chronic primary insomnia.

Material and Methods: Eighty previously sedentary subjects with chronic primary insomnia subjects enrolled in this study, their age ranged from 32-51 year were randomly assigned to life style intervention group (group A, $\mathrm{n}=40$ ) or control group (group B, $n=40$ ). Polysomnographic recordings for sleep quality assessment, IL-6, IL-10 and TNF- $\alpha$ were measured before and at the end of the study after six months.

Results: There was a significant increase in the total sleep duration, sleep efficiency, sleep onset latency and IL-10 in addition to significant reduction in awake time after sleep onset, REM latency, IL- 6 and TNF- $\alpha$ after 6 months of in group(A) as a result of weight loss program; while the results of the control group (group B) were not significant. Also, there were significant differences between both groups at the end of the study.

Conclusion: Life style intervention modulates systemic inflammatory parameters and sleep quality among subjects with chronic primary insomnia.

Keywords: Chronic primary insomnia; inflammatory cytokines; life style intervention; sleep quality.

DOI: https://dx.doi.org/10.4314/ahs.v21i3.31

Cite as: Al-Sharif FM, Abd El-Kader SM. Inflammatory cytokines and sleep parameters response to life style intervention in subjects obese chronic insomnia syndrome. Afri Health Sci. 2021;21(3). 1223-1229. https:// dx.doi.org/10.4314/abs.v21i3.31
\end{abstract}

\section{Introduction}

The global prevalence of chronic insomnia symptoms is about $19 \%$ of people ${ }^{1,2}$. However, insomnia adversely affects general health as it is usually associated with increased rate of morbidly and mortality ${ }^{3,4}$. In addition, obesity is an important risk factor for poor sleep quality and insomnia ${ }^{5-7}$.

Sleep impairment leads to abnormal level of inflammatory cytokines and elevation in blood pressure ${ }^{8,9}$. These abnormal changes may induces coronary artery

\section{Corresponding author:}

Shehab M Abd El-Kader, Department of Physical Therapy, Faculty of Applied Medical Sciences, King Abdulaziz University, P. O. Box 80324, Jeddah, 21589, Saudi Arabia.

Email: salmuzain@kau.edu.sa disease ${ }^{10,11}$. However, low level of systemic inflammation may be an etiological factor in development of cancer $^{12-14}$.

To the best of our knowledge, the present may be the first study for effect of life style intervention on sleep and systemic inflammation parameters among obese subjects with chronic insomnia syndrome. Therefore, the purpose of this investigation was to measure changes in inflammatory cytokines and sleep parameters following weight loss among subjects with chronic primary insomnia.

\section{Patients and methods \\ Subjects}

Eighty previously sedentary subjects having Chronic Primary Insomnia for longer than six months, their age ranged from 32-51 years and participated in this study. 
Inclusion criteria included difficulty initiating sleep, difficulty maintaining sleep, early morning awakenings at least 3 nights during the previous 3 months. However, exclusion criteria included other sleep disorders include moderate or severe apnea, major depression, mental illness, cognitive impairment, cardiovascular disease, heart failure, liver disease, cancer, chronic pain conditions, shift work, regular use of sedatives, hypnotics and painkillers. The participated subjects were enrolled in two groups; group (A) received weight reducing program included training on treadmill and diet regimen. While, group (B) received no weight reducing program included training or treadmill and diet regimen and was the control group. The CONSORT diagram display the essential details of randomization (figure 1). Informed consent was obtained from all participants. This study was approved by the Scientific Research Ethical Committee, Faculty of Applied Medical Sciences at King University.

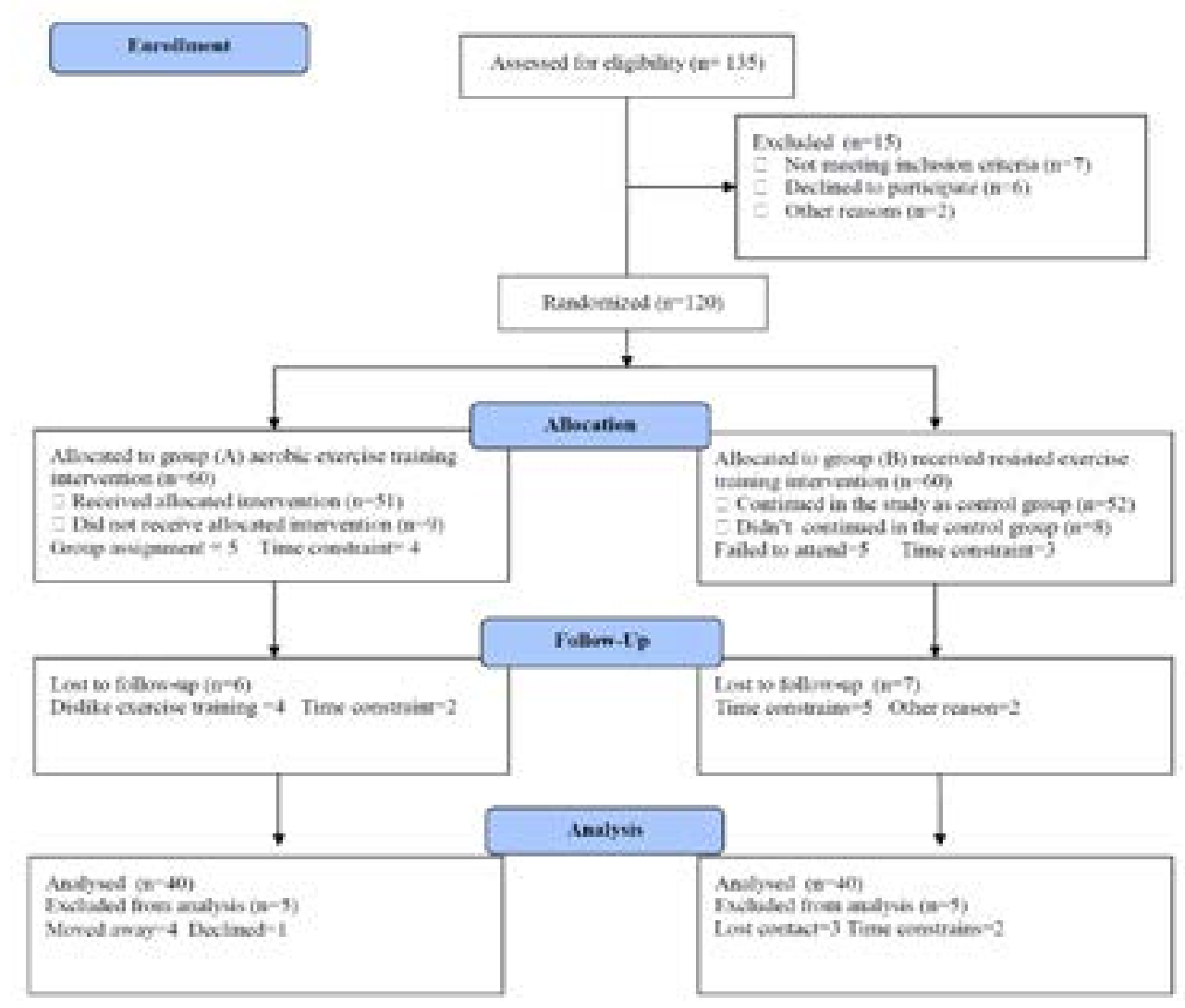

Figure (1): Subjects screening and recruitment CONSORT diagram.

\section{Methods}

\section{Measurements}

A. Sleep measures: Recording of sleep parameters were measured by polysomnographic (PSG) (Philips-Respironics, USA) which was measured over 2 nights before the study and after six months at the end of the study ${ }^{15}$.

B. Inflammatory cytokines: An overnight fasting venous blood samples were drained from the antecubital vein, the centrifuged blood samples were used to analyzed Interleukin-6 (IL-6) and Interleukin-10 (IL-10) levels with "Immulite 2000" immunassay analyzer (Siemens Healthcare Diagnostics, Deerfield, USA). While, ELISA microplate reader (ELX 808; BioTek Instruments, USA) was used to measure tumor necrosis factor-alpha $(\mathrm{TNF}-\alpha)$.

\section{Procedures}

Participants were enrolled randomly into the following groups:

1. Group (A): received weight reducing program included training on treadmill and diet regimen. The aerobic exercise was conducted on treadmill (Enraf Nonium, Model display panel Standard, NR 1475.801, Holland), The training program composed of warming-up for 5 minutes, aerobic exercise for 30 minutes of $60 \%-70 \%$ of maximal heart rate in addition to cooling down for 1o minutes, three sessions/ week for six months. While, the diet control provided 1200 Kilocalories/day for six months.

2. Group (B): received no weight reducing program included training or treadmill and diet regimen and was the control group. 


\section{Statistical analysis}

All the data were collected and entered in IBM SPSS version 21 and analyzed through its statistical package. All the variables were worked out and results were analyzed and presented in tables. The paired " $t$ " test was used to compare the mean values of the investigated parameters in both groups. While Independent " $t$ " test was used for comparison between the two groups $(\mathrm{P}<0.05)$.

\section{Results}

The two groups were considered homogeneous regarding the demographic variables (table 1$)$. The mean age of group, (A) was $46.12 \pm 3.65$ year, and the mean age of group (B) was $44.87 \pm 4.32$ year. There was no significant differences in age, gender, body mass index (BMI), body fat, systolic blood pressure, diastolic blood pressure, hemoglobin and maximal heart rate (HRmax) between both groups.

Table (1): Baseline characteristics of study participants.

\begin{tabular}{|l|c|c|c|}
\hline \multicolumn{1}{|c|}{ Characteristic } & Group (A) & Group (B) & Significance \\
\hline Age (years) & $45.15 \pm 5.27$ & $43.76 \pm 6.12$ & $\mathrm{P}>0.05$ \\
\hline Gender (male/female) & $23 / 17$ & $22 / 18$ & $\mathrm{P}>0.05$ \\
\hline BMI (kg/m $\left.{ }^{2}\right)$ & $32.25 \pm 4.14$ & $32.17 \pm 4.29$ & $\mathrm{P}>0.05$ \\
\hline Waist hip ratio & $0.89 \pm 0.28$ & $0.87 \pm 0.21$ & $\mathrm{P}>0.05$ \\
\hline SBP $(\mathrm{mmHg})$ & $135.61 \pm 6.27$ & $132.43 \pm 7.11$ & $\mathrm{P}>0.05$ \\
\hline DBP $(\mathrm{mmHg})$ & $84.29 \pm 4.31$ & $83.12 \pm 4.17$ & $\mathrm{P}>0.05$ \\
\hline Hb $(\mathrm{gm} / \mathrm{dl})$ & $11.58 \pm 1.59$ & $12.13 \pm 1.36$ & $\mathrm{P}>0.05$ \\
\hline HR $_{\max }(\mathrm{beat} / \mathrm{min})$ & $159.72 \pm 11.61$ & $160.35 \pm 10.49$ & $\mathrm{P}>0.05$ \\
\hline
\end{tabular}

BMI: Body mass index; SBP: Systolic blood pressure; DBP: Diastolic blood pressure; Hb: Hemoglobin; $\mathrm{HR}_{\max }$ : Maximum heart rate.

There was a significant reduction in BMI, CD3, CD4 and CD8 awake time after sleep onset, REM latency, IL- 6 and TNF- $\alpha$ in addition to significant increase in the total sleep duration, sleep efficiency, sleep onset latency and IL-10 after 6 months of in group(A) as a result of weight loss program (table 2); while the results of the control group (group B) were not significant (table 3). Also, there were significant differences between both groups at the end of the study(table 4).

Table (2): Mean value and significance of sleep parameters and inflammatory markers of group (A) before and at the end of the study.

\begin{tabular}{|l|c|c|c|c|}
\hline & \multicolumn{2}{|c|}{ Mean + SD } & $\begin{array}{c}\text { t- } \\
\text { value }\end{array}$ & Significance \\
\cline { 2 - 4 } & $32.25 \pm 4.14$ & $27.93 \pm 3.11^{*}$ & 8.36 & $\mathrm{P}<0.05$ \\
\hline BMI $\left(\mathrm{kg} / \mathrm{m}^{2}\right)$ & $316.73 \pm 28.18$ & $348.45 \pm 21.39^{*}$ & 12.51 & $\mathrm{P}<0.05$ \\
\hline $\begin{array}{l}\text { Total sleep } \\
\text { duration }(\mathrm{min})\end{array}$ & $65.91 \pm 5.14$ & $81.26 \pm 6.25^{*}$ & 9.22 & $\mathrm{P}<0.05$ \\
\hline Sleep efficiency (\%) & $11.12 \pm 3.43$ & $15.28 \pm 3.87^{*}$ & 7.19 & $\mathrm{P}<0.05$ \\
\hline $\begin{array}{l}\text { Sleep onset } \\
\text { latency (min) }\end{array}$ & $78.23 \pm 6.74$ & $62.54 \pm 5.12^{*}$ & 9.14 & $\mathrm{P}<0.05$ \\
\hline $\begin{array}{l}\text { Awake time after sleep } \\
\text { onset }(\mathrm{min})\end{array}$ & $88.42 \pm 7.15$ & $69.31 \pm 6.84^{*}$ & 9.47 & $\mathrm{P}<0.05$ \\
\hline REM sleep latency (min) & $5.24 \pm 1.65$ & $3.26 \pm 1.37^{*}$ & 6.28 & $\mathrm{P}<0.05$ \\
\hline TNF- $\boldsymbol{\alpha}(\mathrm{pg} / \mathrm{mL})$ & $2.83 \pm 0.94$ & $1.71 \pm 0.86^{*}$ & 5.64 & $\mathrm{P}<0.05$ \\
\hline IL-6 $(\mathrm{pg} / \mathrm{mL})$ & $5.72 \pm 1.46$ & $7.98 \pm 1.63^{*}$ & 6.11 & $\mathrm{P}<0.05$ \\
\hline IL-10 $(\mathrm{pg} / \mathrm{ml})$ & & & & \\
\hline
\end{tabular}

BMI: Body mass index; REM: rapid eye movements; TNF- $\alpha$ : tumor necrosis factor - alpha; IL-6: Interleukin-6; IL-10: Interleukin-10; $(*)$ indicates a significant difference between the two groups, $\mathrm{P}<0.05$. 
Table (3): Mean value and significance of sleep parameters and inflammatory markers of group (B) before and at the end of the study.

\begin{tabular}{|l|c|c|c|l|}
\hline & \multicolumn{2}{|c|}{ Mean + SD } & $\begin{array}{c}\text { t- } \\
\text { value }\end{array}$ & Significance \\
\cline { 2 - 4 } & Pre & Post & 0.543 & $\mathrm{P}>0.05$ \\
\hline BMI $\left(\mathrm{kg} / \mathrm{m}^{2}\right)$ & $32.17 \pm 4.29$ & $32.98 \pm 4.31$ & 0.682 & $\mathrm{P}>0.05$ \\
\hline $\begin{array}{l}\text { Total sleep } \\
\text { duration }(\mathrm{min})\end{array}$ & $\begin{array}{c}26.95 \\
26.26 \pm\end{array}$ & $322.75 \pm 27.13$ & 1.24 & $\mathrm{P}>0.05$ \\
\hline Sleep efficiency (\%) & $66.78 \pm 6.15$ & $64.17 \pm 6.11$ & 0.96 & $\mathrm{P}>0.05$ \\
\hline Sleep onset latency (min) & $11.52 \pm 2.61$ & $10.95 \pm 2.42$ & 1.37 & $\mathrm{P}>0.05$ \\
\hline $\begin{array}{l}\text { Awake time after sleep } \\
\text { onset (min) }\end{array}$ & $77.82 \pm 7.19$ & $79.14 \pm 7.35$ & 1.24 & $\mathrm{P}>0.05$ \\
\hline $\begin{array}{l}\text { REM sleep latency (min) } \\
\text { TNF- } \boldsymbol{\alpha}(\mathrm{pg} / \mathrm{mL})\end{array}$ & $90.17 \pm 8.26$ & $91.85 \pm 8.31$ & $\mathrm{P}>0.05$ \\
\hline IL-6 (pg/mL) & $4.92 \pm 1.75$ & $5.11 \pm 1.79$ & 0.541 & \\
\hline IL-10 (pg/ml) & $2.73 \pm 0.78$ & $2.91 \pm 0.82$ & 0.432 & $\mathrm{P}>0.05$ \\
\hline
\end{tabular}

Table (4): Mean value and significance of sleep parameters inflammatory markers in group (A) and group (B) at the end of the study.

\begin{tabular}{|c|c|c|c|c|}
\hline & \multicolumn{2}{|c|}{ Mean + SD } & \multirow{2}{*}{$\begin{array}{c}\mathrm{t}- \\
\text { value }\end{array}$} & \multirow{2}{*}{ Significance } \\
\hline & Group (A) & Group (B) & & \\
\hline BMI $\left(\mathrm{kg} / \mathrm{m}^{2}\right)$ & $27.93 \pm 3.11 *$ & $32.98 \pm 4.31$ & 7.25 & $\mathrm{P}<0.05$ \\
\hline $\begin{array}{l}\text { Total sleep } \\
\text { duration (min) }\end{array}$ & $348.45 \pm 21.39^{*}$ & $322.75 \pm 27.13$ & 11.14 & $\mathrm{P}<0.05$ \\
\hline Sleep efficiency (\%) & $81.26 \pm 6.25^{*}$ & $64.17 \pm 6.11$ & 7.43 & $\mathrm{P}<0.05$ \\
\hline $\begin{array}{l}\text { Sleep onset } \\
\text { latency (min) }\end{array}$ & $15.28 \pm 3.87^{*}$ & $10.95 \pm 2.42$ & 6.38 & $\mathrm{P}<0.05$ \\
\hline $\begin{array}{l}\text { Awake time after sleep } \\
\text { onset (min) }\end{array}$ & $62.54 \pm 5.12^{*}$ & $79.14 \pm 7.35$ & 7.29 & $\mathrm{P}<0.05$ \\
\hline $\begin{array}{l}\text { REM sleep } \\
\text { latency (min) }\end{array}$ & $69.31 \pm 6.84^{*}$ & $91.85 \pm 8.31$ & 8.17 & $\mathrm{P}<0.05$ \\
\hline TNF- $\boldsymbol{\alpha}(\mathrm{pg} / \mathrm{mL})$ & $3.26 \pm 1.37^{*}$ & $5.11 \pm 1.79$ & 5.21 & $\mathrm{P}<0.05$ \\
\hline IL-6 (pg/mL) & $1.71 \pm 0.86^{*}$ & $2.91 \pm 0.82$ & 4.13 & $\mathrm{P}<0.05$ \\
\hline IL-10 (pg/ml) & $7.98 \pm 1.63^{*}$ & $5.65 \pm 1.29$ & 5.28 & $\mathrm{P}<0.05$ \\
\hline
\end{tabular}

BMI: Body mass index; REM: rapid eye movements; TNF- $\alpha$ : tumor necrosis factor - alpha; IL-6: Interleukin-6; IL-10: Interleukin-10; $(*)$ indicates a significant difference between the two groups, $\mathrm{P}<0.05$.

\section{Discussion}

Sleep loss alters molecular processes that induce low grade of systemic inflammation ${ }^{16}$ as well as increased circulating levels of inflammatory markers (i.e., IL-6, tumor necrosis factor- alpha TNF- $\alpha$, C-reactive protein) $)^{17,18}$. Therefore, the aim of this study was to measure chages in inflammatory cytokines and sleep parameters following weight loss among subjects with chronic primary insomnia.

Concerning sleep quality parameter, the present study found significant improvement in all sleep parameters as a result of weight loss in $\operatorname{group}(\mathrm{A})$, these results are in line with Tan et al. reported that modest energy re- striction as a result of six-month individualized diet intervention shorten sleep onset latency in overweight and obese men with insomnia symptoms ${ }^{19}$. In addition, Tan and colleagues reported that a six months weight reducing program significantly improved sleep quality parameters in obese men enrolled ${ }^{20}$. However, Passos et al. stated that a four-months aerobic exercise training program resulted in improvement in sleep parameters among subjects with chronic primary insomnia ${ }^{21}$. Many mechanisms may be responsible for improvement in sleep parameters as a result of weight reduction included changes in composition of gut microbiota and specific hormones in addition to anti-inflammatory cytokines and endorphin secretion ${ }^{22-24}$. 
To our knowledge, this is limited number of researches that measure inflammatory cytokines response to intentional weight loss in subjects with chronic primary insomnia. Our results indicate that intentional weight loss modulated systemic inflammation markers. These results are in line with several previous studies reported that CRP and TNF- $\alpha$ are known to decrease by weight loss ${ }^{25-27}$. Many previous studies proved that weight reducing program was an effective treatment modality in obese subjects with OSA ${ }^{28-30}$. However, lifestyle modification modulated inflammatory cytokines in diabetic patients ${ }^{31}$. Moreover, Cotie et al. proved that 4-months of exercise training and diet regimen improved inflammatory markers as a result of weight reduction among obese women ${ }^{32}$. However, Lang et al. reported that two months weight control resulted in modulation of blood lipids and inflammatory markers of obese subjects ${ }^{33}$. While, Madsen et al. stated that inflammatory cytokines significantly improved as a result of weight loss in obese individuals ${ }^{34}$. Sheu et al. enrolled 21 non-diabetic obese women in a three months weight reducing program which resulted in significant reduction in TNF- $\alpha$ and IL- $6{ }^{35}$. Finally, Sahlman et al. enrolled overweight patients with mild OSA in a one year supervised lifestyle intervention which resulted in reduction of inflammatory cytokines ${ }^{36}$. The possible mechanism of inflammatory cytokines modulation as result of weight reducing program may be due to reduced fat mass ${ }^{37-40}$.

\section{Conclusion}

Life style intervention modulates systemic inflammation and sleep parameters among obese subjects with Chronic Primary Insomnia.

\section{Acknowledgment}

This project was funded by the Deanship of Scientific Research (DSR) at King Abdulaziz University, Jeddah, under grant no. (G: 5-290-41). The authors, therefore, acknowledge with thanks DSR for technical and financial support.

\section{Conflict of interest}

None declared.

\section{References}

1. Chung KF, Yeung WF, Ho FY, Yung KP, Yu YM, Kwok CW. Cross-cultural and comparative epidemiology of insomnia: The Diagnostic and statistical manual (DSM), International classification of diseases (ICD) and International classification of sleep disorders (ICSD). Sleep Med. 2015, 16, 477-482.
2. Khan M, Aouad R. The Effects of Insomnia and Sleep Loss on Cardiovascular Disease. Sleep Med Clin 12 (2017) 167-177

3. Tobaldini E, Costantino G, Solbiati M, et al. Sleep, sleep deprivation, autonomic nervous system and cardiovascular diseases. Neurosci Biobehav Rev 2017;74(Pt B):321-9.

4. Bathgate CJ, Edinger JD, Wyatt JK, Krystal AD. Objective but not subjective short sleep duration associated with increased risk for hypertension in individuals with insomnia. Sleep. 2016;39(5):1037-1045.

5. Broussard JL, Van Cauter E. Disturbances of sleep and circadian rhythms: novel risk factors for obesity. Curr Opin Endocrinol Diabetes Obes 2016;23(5):353-9.

6. Palm A, Janson C, Lindberg E. The impact of obesity and weight gain on development of sleep problems in a population-based sample. Sleep Med. 2015, 16, 593-597. 7. Vgontzas, A.N.; Lin, H.M.; Papaliaga, M.; Calhoun, S.; Vela-Bueno, A.; Chrousos, G.P.; Bixler, E.O. Short sleep duration and obesity: The role of emotional stress and sleep disturbances. Int. J. Obes. 2008, 32, 801-809. 8. Mullington JM, Simpson NS, Meier-Ewert HK, Haack M. Sleep loss and inflammation. Best Pract Res Clin Endocrinol Metab. 2010;24(5): 775-784.

9. Patel SR, Zhu X, Storfer-Isser A, et al. Sleep duration and biomarkers of inflammation. Sleep. 2009;32(2):200204.

10. Chrysohoou C, Kollia N, Tousoulis D. 2018. The link between depression and atherosclerosis through the pathways of inflammation and endothelium dysfunction. Maturitas 109, 1-5.

11. Halaris A.2017. Inflammation-associated co-morbidity between depression and cardiovascular disease. Curr. Top. Behav. Neurosci. 31, 45-70

12. Li J, Jiao X, Yuan Z, Qiu H, Guo R. 2017b. C-reactive protein and risk of ovarian cancer. Medicine (Baltimore) 96, e7822.

13. Chan DSM, Bandera EV, Greenwood DC, Norat T. 2015. Circulating C-Reactive Protein and breast cancer risk-Systematic literature review and meta-analysis of prospective cohort studies. Cancer Epidemiol. Biomarkers Prev. 24, 1439-1449.

14. Zheng R.-R, Huang M, Jin C, Wang H.-C, Yu J-T, Zeng L-C, Zheng F-Y, Lin F. 2016. Cervical cancer systemic inflammation score: a novel predictor of prognosis. Oncotarget 7, 15230-15242.

15. Rechtschaffen A, Kales AA. Manual of standardized terminology, techniques, and scoring system for sleep stages of human subjects. Los Angeles: Brain Information Service/Brain Research Institute/UCLA; 1968.

16. Irwin MR, Wang M, Campomayor CO, Colla- 
do-Hidalgo A, Cole S. Sleep deprivation and activation of morning levels of cellular and genomic markers of inflammation. Arch Intern Med 2006;166:1756-62 PubMed .

17. Vgontzas AN, Zoumakis M, Papanicolaou DA, Bixler EO, Prolo P, Lin HM, et al. Chronic insomnia is associated with a shift of interleukin- 6 and tumor necrosis factor secretion from nighttime to daytime. $\mathrm{Me}$ tabolism 2002;51:887-92 PubMed .

18. Shearer W'T, Reuben JM, Mullington JM, Price NJ, Lee BN, Smith EO, et al. Soluble TNF-alpha receptor 1 and IL-6 plasma levels in humans subjected to the sleep deprivation model of spaceflight. I Allergy Clin Immunol 2001;107:165-70.

19. Tan X, Alén M, Wang K, Tenhunen J, Wiklund P, Partinen M, Cheng S. Effect of Six-Month Diet Intervention on Sleep among Overweight and Obese Men with Chronic Insomnia Symptoms: A Randomized Controlled Trial. Nutrients. 2016 Nov 23;8(11). pii: E751. 20. Tan X, Saarinen A, Mikkola TM, Tenhunen J, Martinmäki S, Rahikainen A, Cheng S, Eklund N, Pekkala S, Wiklund P, Munukka E, Wen X, Cong F, Wang X, Zhang Y, Tarkka I, Sun Y, Partinen M, Alen M, Cheng $S$. Effects of exercise and diet interventions on obesity-related sleep disorders in men: study protocol for a randomized controlled trial. Trials. 2013 Jul 26;14:235. 21. Passos GS, Poyares D, Santana MG, Teixeira AA, Lira FS, Youngstedt SD, dos Santos RV, Tufik S, de Mello MT. Exercise Improves Immune Function, Antidepressive Response, and Sleep Quality in Patients with Chronic Primary Insomnia. Biomed Res Int. 2014; 2014:498961.

22. Driver HS, Taylor SR (2000) Exercise and sleep. Sleep Medicine Reviews 4: 387-402.

23. Yang, P.Y., Ho, K.H., Chen, H.C., Chien, M.Y., 2012. Exercise training improves sleep quality in middle-aged and older adults with sleep problems: a systematic review. J. Physiother. 58 (3) 157-163.

24. Kapsimalis F, Basta M, Varouchakis G, Gourgoulianis K, Vgonzas A, Kryger M. Cytokines and pathological sleep. Sleep Med 2008; 9:603-14 PubMed .

25. Cottam DR, Mattar SG, Barinas-Mitchell E, Eid G, Kuller L, Kelley DE, et al. The chronic inflammatory hypothesis for the morbidity associated with morbid obesity: implications and effects of weight loss. Obes Surg 2004;14:589-600.

26. Visser M, Bouter LM, McQuillan GM, Wener MH, Harris TB. Elevated C-reactive protein levels in overweight and obese adults. JAMA 1999;282:2131-5 PubMed .
27. Selvin E, Paynter NP, Erlinger TP. The effect of weight loss on C-reactive protein: a systematic review. Arch Intern Med 2007;167:31-9 PubMed .

28. Tuomilehto HP, Seppa" JM, Partinen MM, Peltonen M, Gylling H, Tuomilehto JO, et al. Lifestyle intervention with weight reduction: first-line treatment in mild obstructive sleep apnea. Am J Respir Crit Care Med 2009;179:320-7 PubMed .

29. Foster GD, Borradaile KE, Sanders MH, Millman R, Zammit G, Newman AB, et al. Sleep AHEAD research group of look AHEAD research group. A randomized study on the effect of weight loss on obstructive sleep apnea among obese patients with type 2 diabetes: the Sleep AHEAD study. Arch Intern Med 2009;169:1619-26 PubMed.

30. Johansson K, Neovius M, Lagerros YT, Harlid R, Ro"ssner S, Granath F, et al. Effect of very low energy diet on moderate to severe obstructive sleep apnoea in obese men: a randomized controlled trial. BMJ 2009;339:b4609.

31. Herder C, Peltonen M, Koenig W, Su"tfels K, Lindstro"m J, Martin S, et al. Finnish Diabetes Prevention Study Group. Antiinflammatory effect of lifestyle changes in the Finnish Diabetes Prevention Study. Diabetologia 2009;52:433-42.

32. Cotie LM, Josse AR, Phillips SM, MacDonald MJ. Endothelial function increases after a 16-week diet and exercise intervention in overweight and obese young women. Biomed Res Int. 2014; 2014:327395.

33. Lang HF, Chou CY, Sheu WH, Lin JY. Weight loss increased serum adiponectin but decreased lipid levels in obese subjects whose body mass index was lower than $30 \mathrm{~kg} / \mathrm{m}^{2}$. Nutr Res. 2011 May;31(5):378-86.

34. Madsen EL, Rissanen A, Bruun JM, et al. Weight loss larger than $10 \%$ is needed for general improvement of levels of circulating adiponectin and markers of inflammation in obese subjects: a 3-year weight loss study. Eur J Endocrinol. 2008; 158(2):179-187.

35. Sheu WH, Chang TM, Lee WJ, Ou HC, Wu CM, Tseng LN, Lang HF, Wu CS, Wan CJ, Lee IT. Effect of weight loss on proinflammatory state of mononuclear cells in obese women. Obesity (Silver Spring). 2008 May; 16(5):1033-8.

36. Sahlman J, Seppä J, Herder C, Peltonen M, Peuhkurinen K, Gylling H, Vanninen E, Tukiainen H, Punnonen K, Partinen M, Uusitupa M, Tuomilehto H. Effect of weight loss on inflammation in patients with mild obstructive sleep apnea. Nutr Metab Cardiovasc Dis. 2012 Jul;22(7):583-90.

37. Mathur M, Pedersen B. Exercise as a mean to con- 
trol low-grade inflammation. Mediators Inflamm 2008; 39. Wang J, Song H, Tang X, Yang Y, Vieira VJ, Niu Y, 2008:109502.

Ma Y. Effect of exercise training intensity on murine $\mathrm{T}$

38. Timmerman K, Flynn M, Coen P, Markofski M, regulatory cells and vaccination response. Scand J Med Pence B. Exercise training-induced lowering of inflam- Sci Sports 2012; 22(5):643-52.

matory (CD14+CD16+) monocytes: a role in the an- 40. Hong S, Dimitrov S, Pruitt C, Shaikh F, Beg N. Benti-inflammatory influence of exercise? Leukoc Biol 2008; efit of physical fitness against inflammation in obesity: 84: $1271-1278$. role of beta adrenergic receptors. Brain Behav Immun. 2014;39:113-20 PubMed 